\title{
RECONVERSION DE LA IGLESIA \\ DEL CONVENTO DE SANTO DOMINGO (LIMA) \\ DURANTE EL SIGLO XVII
}

Las grandes iglesias conventuales peruanas muestran actualmente la planta basilical de tres naves abiertas con crucero interno. No fue ésta, sin embargo, la forma de planta con que se edificaron inicialmente esas iglesias durante el siglo XVI. Con excepción de alguna que ctra, como la tercera del colegio jesuítico de San Pablo en Lima, casi todas lais grandes iglesias virreinales peruanas llegaron a adquirir la planta basilical mediante un proceso de reconversión interna. Constituye la reconversión de la planta una de las expresiones más características de la arquitectura virreinal peruana; pues durante cl siglo XVII se transformaron internamente todas las grandes iglesias hasta el punto de que ha desaparecido en el virreinato del Perú todo vestigio de la platan gótico-isabelina de las iglesias construidas durante el siglo XVI con una sola nave abierta, sin crucero y con series laterales de capillas- hornacinas profundas cerradas con rejas de madera. Sólo podemos vislumbrar cómo había sido aquella planta gótico-ísabelina de las grandes iglesias virreinales de la primera mitad del siglo XVII mediante la descripción de los cronistas religiosos de aquella época, y también por el ejemplo de las pequeñas iglesias gótico-isabelinas virreinales sin capillas-hornacinas profundas y con un arco toral intercalado entre la capilla mayor y la nave de los fieles, de las que quedan tociavía valiosos ejemplares en la sierra peruana.

En la iglesia de La Merced en Lima se llevó a cabo la reconversión plena entre los años de 1608 y 1614, aunque se completó el proceso de cerrar las nuevas cubiertas después 
de 1628; en la iglesia de San Francisco se hizo a partir de 1657; y las otras iglesias limeñas de San Agustín y de Santo Domingo no llegaron a realizar la reconversión sino a finales cel siglo XVII.

La transformación de la iglesia de Nuestra Señora del Rosario, en el convento de Santo Domingo, resulta paradig-mática porque muestra una planta arquitectónica cue fue adaptándose progresivamente hasta llegar a la conformación actual. Y en cuanto a sus cubiertas, anticipa la evolución desde las cubiertas mudéjares de lacería hasta las bóvedas vaídas da crucería labradas en madera de cedro y yeso, que después se aplicaron con notorio éxito en la reconstrucción de la catedral de Lima subsiguiente al terremoto de 1687.

Hizo posible las transformaciones que analizamos ahora ia singular circunstancia de haber residido como religioso conventual del convento de Santo Domingo el famoso alarife fray Diego Maroto, maestro mayor de fábricas 1eales, y figura predominante en los quehaceres arquitectónicos limeños durante la segunda mitad del siglo XVII. No fue Maroto iniciador de nuevas tendencias en cuanto a la conformación de la planta de las iglesias limeñas, ya que ello venía aplicándose desde principios del siglo XVII; pero, al menos, se dio cuenta de que la planta de la iglesia de su convento recesitaba ser modificada, porque resultaba anticuada e inadecuada para las exigencias de su tiempo; y supo resolver el problema técnico de adecuarla con el menor costo posible, pero con notorio acierto. La solución por él introducida resultó tan apropiada que ha desorientado a historiadores del arte tan competentes como el norteamericano Wethey.

Encontramos la información básica para conocer la planta inicial de esta iglesia de Nuestra Señora del Rosario en las descripciones de Lizárraga ${ }^{1}$, Bernabé Cobo $^{2} ; \mathrm{y}, \in$ n menor va-

1 Lizárraga, Fr. Reginaldo de: Descripción y población de las Indias, «Revista del Instituto Histórico del Perúw, por Carlos A. Romero, Lima, imprenta América, 1908, cap. XXII, XXIII y XXIV, pags. 30-34.

2 Cobo, B.: Historia de la lundación de Lima, en «Monografías históricas sobre la ciudad de Limax, t. I, Lima, 1935, lib. III, cap. III, págs. 237.239. 
lía, en la crónica de Vázquez de Espinosa ${ }^{3}$, referentes todas ellas a la primera etapa anterior a la reconstrucción de la planta; además de los conciertos notariales publicados por el padre Domingo Angulo ${ }^{4}$. Para analizar la reconstrucción sucesiva debemos acudir a la obra clásica del cronista dominicano Meléndez, tanto en sus descripciones, como en el famoso plano del convento de Santo Domingo ; además de algunos protocolos notariales mencionados por el dominico padre Angulo, pero todavía utilizados en lo que concierne a la evolución arquitectónica de la iglesia del Rosario.

El historiador del arte don Enrique Marco Dorta ha señalado algunas características del primer templo dominicano de Lima, anterior a las reformas subsiguientes al terremoto de 1678, tomando como base las descripciones de los cronistas ccntemporáneos. Escribe así: «Relacionando estos datos podemos describir el templo como una iglesia de una gran nave con capillas, abovedadas éstas y el presbiterio, y cubierta la rave central con alfarjes, resultando así de un tipo góticomudéjar muy de acuerdo con la época en que fue construida» ${ }^{\circ}$. Refiérese esta interpretación más bien a las cubiertas que a la planta misma; lo cual no obsta para que también bajo este aspecto merezca ser calificada esta iglesia dominicana como de tı azado gótico-isabelino.

El historiador dominico padre Angulo pudo habernos esbozado la historia completa de la reconversión de su iglesia del Rosario; pero, lejos de ofrecernos una visión integral, se limitó a presentar dos versiones fragmentadas e independientes, desprovistas de las referencias documentales que las avalaban; con el agravante de aparecer distanciadas una de otra

3 Vázquez de Espinosa, A.: Compendio y descripción de las Indias occidentales, Washington, 1948, lib. IV, cap. 21, págs. 404-405.

4 Angulo, D.: El primitivo estilo de lal iglesia de Santo Domingo, «Revista del Archivo Nacional del Perim, t. II, Lima, 1921, pars. 527-530. Del mismo: La iglesia de Santo Dominco en la ciudad de los Reyes, «Revista del Archivo Nacional del Perún, t. XII, 1939, págs. 221.228.

5 Meléndez, J.: Tesoros verdaderos de las Indias, t. I, Roma, imprenta de Nicoláa Angel Tinassio, 1681, especialmente par. 55.

6 Marco Dorta, E.: Historia del arte hispanoamericano, Barcelona, 1945, t. I, pás. 625. 
treinta años. La primera versión aparece en su obra: La Orden de Santo Domingo en el Perú, y en ella atribuye al provincial dominico padre Juan de los Ríos la reconstrucción de la iglesia por los años de su gobierno entre el 7 de enero de 1677 y el 24 de julio de $1681^{7}$. En esta versión se ha basado el historiador Jorge Bernales Ballesteros ${ }^{8}$. Aparece la segunda versión ofrecida por Domingo Angulo en el artículo publicado en 1939, donde atribuye al auspicio del prior de Santo Domingo fray Diego Morato la construcción del crucero de la iglesia por los años de 1683 y 1684 ; es decir, después de publicado el primer tomo de la obra de Meléndez con el plano general del convento e iglesia ${ }^{\circ}$. Ciertas confusiones interpretativas en que se enredan los historiadores del arte virreinal provienen de esta dualidad incoherente de versiones ofrecidas por el padre Domingo Angulo.

Sin duda, el más confundido ha resultado Wethey al afirmar muy confiadamente que la planta de la iglesia de Santo Domingo ha permanecido la misma a lo largo de todo el tiempo, desde su inicio en la quinta década del siglo XVI ${ }^{10}$. Según este punto de vista de Wethey, la frase del cronista Lizárraga: «comenzó el edificio de la iglesia de bóveda de tres naves», concordaría con el famoso plano de Meléndez publicado en 1681; mientras que le parece a Wethey inexacta y desconfiable la minuciosa descripción ofrecida por Bernabé Cobo; al mismo tiempo que no parece muy dispuesto a sacar conclusión alguna de la información proporcionada por Domingo Angulo en 1939; además de no haber tenido en cuenta para nada la información de este historiador dominico en 1908.

Las confusiones históricas originadas en los sucesivos y no concordados escritos del padre Angulo vuelven a apare-

7. Angulo, D.: La orden de Santo Domingo en el Perú, Lima, 1908, págs. 214-215; véase también págs. 213 y 217.

8 Bernales Ballesteros, J.: Lima, la ciudad y sus monumentos, Sevilla, 1972, pá. 248.

9 Angulo: La iglesia de Santo Domingo, pág. 222.

10 Wethey, H. E.: Colonial architecture end sculpture in Peru, Cambridge, Massachusetts, 1949, pág. 268. Recopilando su análisis acerca de la iglesia de Santo Domingo, anota: afloor plan of about 1540\%, pág. 269. 
cer en el estudio de la doctora Martha Barriga acerca de la iglesia de Santo Domingo ${ }^{11}$. Por un lado, parece suponer que cl crucero de la iglesia dominicana existía antes del terremoto de 1678 , porque afirma que a consecuencia de este terremoto, tue necesario derribar la capilla mayor y ello «obligó a reediiicar las capillas laterales a la mayor y las de las naves late1ales que formaban el crucero» ${ }^{12}$. Por otro lado, atribuye al prior de Santo Domingo, padre fray Diego Morato, la ampliación del crucero en 1681, que en realidad se redujo a la apertura de los muros divisorios entre el crucero y las capillas de San Juan Bautista y del Rosario, que todavía aparecen cerrados en el plano de Meléndez ${ }^{13}$. Aunque la doctora Barriga cita el testimonio de Bernabé Cobo, no se ha detenidc a confrontar la planta descrita en el primer tercio del siglo XVII con el plano de Meléndez de 1681; y tampoco ha estudiado en qué tsempo se construyó el famoso crucero, si bien supone que cxistía desde antes de 1678. La tesis de Wethey acerca de la permanencia de la planta de la iglesia desde el principio ha sido reactualizada en el estudio de la doctora Barriga.

Estamos actualmente en condiciones de descalificar por completo la creencia de Wethey; y de afirmar que la planta cie la iglesia de Santo Domingo ha variado fundamentalmente durante la segunda mitad del siglo XVII. Comenzamos por restituir plena confiabilidad a la descripción del cronista contemporáneo Bernabé Cobo: «La iglesia es muy grande y de costosa fábrica; de una nave con dos órdenes de capillas por los lados; éstas son bóvedas curiosamente labradas, y la nave de enmedio cubierta de madera y lacería curiosa; la capilla 1nayor es de bóveda y para tan grande iglesia es tenida por pequeña» ${ }^{14}$. A pesar de lo que opine Wethey, la descripción

\footnotetext{
11 Barriga Tello, M. I.: La iglesia de Santo Domingo de Lima durante el siglo XVII, "Letras», núm. 88-89, Lima, 1982-1985, págs. 7-20.

12 Ibídem, págs. 10-11. No se sabe qué capillas laterales de la mayor sean esas, pues ni las representa el plano de Meléndez ni existen actualmente.

13 Ibídem, pág. 14. La autora confunde reiteradamente al alarife lego Diego Maroto, con el padre maestro Diego Morato.

14 Cobo: Historia..., pág. 237.
} 
de Lizárraga, hijo del mismo convento, concuerda a cabalidad con la de Cobo; dice así el cronista dominico:

“...comenzó el edificio de la iglesia de bóveda de tres naves, e hizo la mitad de la iglesia, dejando los cimientos de lo restante sacados... sólo una falta se le pone, y sin envidja, que la capilla mayor es pequeña, la cual tiene un retablo muy aventajado" 15.

Cuando Lizárraga afirmaba que la iglesia del Rosario se lizo de tres naves, no estaba indicando con ello que las tres raves estuvieran abiertas y comunicadas; pues sabemos por ctros documentos que las dos naves laterales estaban ocupadas por capillas cerradas e incomunicadas entre sí, de tal modo cue mostraba la iglesia una planta típicamente gótico-isabelina. Refiriéndose el dominico Lizárraga a la totalidad del edificio de su iglesia, mencionaba las tres naves, pero no su disponibilidad para estar abiertas al tránsito público. El cronista Vázquez de Espinosa empleaba una terminología semejante para describir la catedral de Lima:

"su fábrica es maravillosa de bóvedas de crucería, crden jónico, de cinco naves, las tres claras a que corresponden las tres puertas a la plaza, y las otras dos naves de capillas del mismo orden conforme a buen arte" 18.

Al mencionar simultáneamente Lizárraga y Cobo que la capilla mayor de Santo Domingo era pequeña, señalaban dos defectos estructurales: primeramente, que el 1,resbiterio resultaba poco profundo. No sabemos cuál sería entonces la forma de su planta; pero nos aventuramos mucho si suponemos que el muro testero tenía forma ochavada en las esquinas tal y cual se estilaba en las construcciones del siglo XVI, de las que todavía quedan algunos ejemplares en la arquitectura virreinal peruana del Collao, precisamente la zona que tuvieron encomendada los dominicos doctrineros.

Consistió la segunda deficiencia en que la iglesia carecía entonces de crucero. Todas las capillas-hornacinas latera-

15 Lizárraga: Descripcionn..., pirgs. 30-31.

16 Várquez de Espinosa: Compendio..., lib. IV, cap. 19, núm. 1234, pre. 401. 
les, incluyendo las de Agüero y Aliaga, tenían las mismas dimensiones, y estaban cerradas frente a la nave zentral por re;as de madera, e incomunicadas entre sí por muros continuos. Todavía se conservan cerradas en la iglesia de Santo Domingo İas capillas-hornacinas situadas debajo del coro, de las que, .egún informa Lizárraga, una cra de indios y otra de negros ${ }^{17}$. De esta suerte, la iglesia del Rosario sólo tenía habilitada para uso del público la nave central, larga y estrecha en toda su iongitud, y más corta de lo que quedó después de las remodelaciones que analizaremos, sin cimborrio ni cúpuia, y toda ella cubierta de techumbre mudéjar desde la capilla mayor hasta ei muro de los pies. Sabemos, por otro lado, que la novedad del crucero comenzó a ser introducida en la arquitectura vireinal peruana a principios del siglo XVII con la iniciación de la planta basilical; y así fueron ampliadas las iglesias de La Merced y San Francisco, a las que siguió la del Colegio de San Pablo.

El cronista Cobo es muy explícito al describir el nuevo crucero abierto a principios del siglo XVII en las iglesias limeñas de San Francisco y de La Merced; en cambio no lo menciona para nada en la iglesia de Santo Domingn. Otros documentos que serán analizados adelante informan que el crucero dominicano se abrió en época posterior; pero nos interesa ahora destacar que la planta inicial de Santo Domingo no requería inicialmente del crucero: era una planta gótico-isabelina, descrita por Cobo con toda exactitud. Nos encontramos pues, ante dos momentos históricos distintos de la planta en la iglesia de Santo Domingo, ambos acreditados fehacientemente por testimonios contemporáneos de los hechos: el primero es el de la planta gótico-isabelina, de una sola nave abier: $\mathrm{a}$ sin crucero y con capillas-hornacinas cerradas y capilla mayor pequeña; el segundo es el representado hacia 1681 por el plano de Meléndez, de una planta basilical con tres naves abiertas y crucero interno, faltando por abrir dos muros trans-

17 Lizárraga: Descripción..., cap. XXIV, pág. 34. 
versales entre el crucero y las dos capillas adjuntas. La existencia de estos dos momentos estructurales diferentes y sucesivos en la iglesia de Santo Domingo nos plantea el problema histórico, soslayado por algunos historiadores y entreverado artificiosamente por otros, de determinar cuándo y cómo se llevó a cabo la reconversión de la planta gótico-isabelina inicial en la planta basilical posterior. Ádelantamos que se trata de un proceso de reconversión gradual de la planta, no de la nueva construcción en el mismo sitio de otra planta distinta; porque la iglesia dominicana conserva todavía gran parte de su perí1netro murario inicialmente construido en el siglo XVI.

La planta de Santo Domingo no ha permanecido inmutabile, ni siquiera desde sus comienzos, hasta las giandes reformas introducidas en el último tercio del siglo XVII. También curante la primera mitad del mismo siglo se ejecutaron algunas modificaciones de la planta en la iglesia dominicana, las que si bien no afectaban a la totalidad del edificio, condicionaron su evolución posterior. Estas primeras reformas parciales han permanecido intangibles hasta el día de hoy; y puesto que este sector conserva la traza que adquirió entonces, el sector de los pies de la iglesia por ellas afectado permanece tal cual quedó por aquellos años. Las que parecían reformas parciales e inconclusas, derivaron en definitivas, al no ser acompañadas por otras complementarias; y con su provisionalidad consolidada han impedido que la iglesia de Santo Domingo logre el desarrollo grandioso que ostentan las restantes iglesias conventuales mayores de San Agustín, San Francisco y La Merced. Las reformas de la segunda mitad del siglo XVII se desplazaron, en cambio, hacia el sector de cabecera en busca de mayor capacidad espacial; pero sin dar acogida al avance arrollador del barroco limeño en las demás iglesias.

Los mayordomos de la poderosa cofradía de Nuestra Señora del Rosario, cuando todavía ocupaban el lugar que aparece señalado en el plano de Meléndez, iniciaron una pequeña reforma, a manera de anticipo de la que después se generalizó en todas las capillas laterales. Se trataba de abrir la 
comunicación entre su propia capilla y la contigua hacia los pies de la iglesia, denominada capilla de las Reliquias, mediante la perforación de un arco en el muro divisorio. La apertura de comunicación entre las dos capillas cerradas de la nave lateral constituye una de las reformas efectuadas a principios del siglo XVII en la iglesia limeña de La Merced con el objeto de transformar su planta gótico-isabelina en planta basilical de tres naves abiertas.

La apertura del arco entre lás capillas del Rosario y de Las Reliquias la contrató el mayordomo Gil Gómez con el alarife Antonio Mayordomo por concierto notarial de 7 de noviembre de $1608^{18}$. Parece que este Antonio Mayordomo era experto en abrir arcos entre capillas adjuntas, porque también realizó otra operación semejante entre dos capillas cerradas de la nave de la epístola en la iglesia limeña de la Merced, según concierto notarial de 16 de abril de $1611^{19}$. El arco desplazaba al muro lateral divisorio entre las dos capillas dominicanas. Se asentaría sobre dos pilastras: «la una arrimada al pilar toral y la otra arrimada a la pared del claustro». Esto significa que el arco cubría toda la anchura de la nave lateral actual, de tal forma que constituía el principio de una futura planta basilical de naves abiertas y comunicadas entre sí. Pero además, este arco había de tener «la montea tal y de la manera ; del tamaño del arco que está en la capilla de Ntra. Señora por la parte del cuerpo de la iglesia»; de tal modo que, por deducción, también este arco de la iglesia abarcaría toda la anchura entre los dos pilares. En realidad, el arco entre las dos capillas era doble, debido a que el muro a sustituir tenía gran anchura y ello permitía formar dos arcos contiguos, uno a cada lado del viejo muro. Lo importante es que estos dos arcos y el del frente de la capilla del Rosario «estén a un mismo alto y a una montea».

No quedaban llanos y lisos estos arcos ni en el intradós

18 Archivo General Notarial (en adelante AGN), escribano Cristóbal Aguilar Mendieta, 1607-1608, protocolo 50, fol. $940 \mathrm{vta}$. Se incluye como Anexo documental, I.

19 AGN, escribano Diego Rodrlguez Torquemada, 1609-1611, protocolo 1672, fol. $6 \%$. 
ni en sus pilastras de sustentación, antes bien tenían ornamenlación renacentista de artesones. El concierto dice que el in11 adós «por la parte de abajo de la mocheta del arco ha de llevar la talla que tiene el dicho arco referido»; además de que «las pilastras ha de ser con artesón cerrado con sus florones de yesería todo curioso y perfecto».

Son importantes los detalles técnicos de la construcción. No derribaron previamente el muro divisorio, sino que lo aprovecharon como sustento y cimbra para los arcos a construir: «y se entiende y es declaración que este arco le he de cerrar sobre la pared que es donde está hoy que ha de servir de cimbra volviendo como me obligo a macizar lo que picare y cabare de la dicha pared hasta que de todo punto el dicho arco esté seco y embebido». Es posible que este sistema de construir arcos sobre el muro preexistente, que ahorra la cimbra de madera, se haya empleado en otras ocasicnes al abrir capillas laterales a la libre comunicación para formar naves iaterales abiertas. Otro trabajo importante consistió en consolidar y trabar firmemente el trasdós de los riuevos arcos con los muros contiguos en la base de las bóvedas de las dos capillas, denominados «formas»: «de manera que no corran ningún detrimento crucero ni forma ni rampante».

Había de quedar el intradós de los dos nuevos arcos dispuesto no sólo como buena obra de albañilería, sino también preparado para recibir ornamentación de pinturas: «de manera que esta obra esté acabada en perfección y ccnforme arte pincelada cabayada bruñida y enlustrada por si se quiere dorar con su talla». En efecto, los mayordomos de la cofradía del Rosario se concertaron al final de las obras, el día 13 de junio de 1609, con el pintor Pedro Pablo Morón, discípulo de Pérez de Alesio, para encomendarle la pintura de la bóveda y del arco que se había abierto en la capilla de las Reliquias, junto a la del Rosario ${ }^{20}$. Aquella iniciativa de abrir el muro đivisorio entre dos capillas afectó entonces al ámbito territo-

20 AGN, escribano Juan de Zamudio, 1608.1609, protocolo 2020, fol. 446. 
rial dominado por la poderosa cofradía de Nuestra Señora del Rosario; pero señaló el camino a seguir para conectar toc'os los ambientes laterales en forma de naves abiertas, al modo como se estaba realizando entonces en la iglesia de La Merced. Algunos años más tarde de esta primera reforma, pretendieron los dominicos aplicar la misma solución en mayor escala; pero no consiguieron completar la reform $\lambda$ integral de las capillas laterales en toda la iglesia, en parte debido a la configuración de la planta inicial, y en parte por las fuertes interferencias institucionales de la cofradía del Rosario. Al final tuvieron los dominicos que transigir con la oposición de la cofradía, aun a riesgo de fracasar de momento en su intento de modernizar la planta de la iglesia. Por concierto notarial del 17 de noviembre de 1638, llegaron estos frailes y la cofracía a una transacción que frenaba por entonces la expansión del libre tránsito por las naves laterales de la ig!esia. Aporta este concierto notarial informaciones muy valiosas para conocer el estado de la planta en la iglesia durante la primera mitad del siglo XVII. Dice así el texto del concierto:

"... el 31 de julio de 1627 ante Juan de Valenzuela el Convento ...vendio a las hijas e hijos de los espoñoles veinte y cuatros y esclavos de Nuestra Señora del Rosario una capilla en la iglesia de el junto a la puerta por donde se entra al claustro a la mano izquierda dondo colocaron la dicha imagen diciendo sus misas... do que están debiondo setecientos y estando en este estado por buen acuerdo del Convento se derribó la pared de la dicha capilla con las demás cuya obra al presente se está haciendo de suerte que por una y por otra parte corren las naves derechas, con lo cual la dicha iglesia queda más alegre y vistosa... y así mismo se ha hecho una ventana corredor on el antecoro frontero de la dicha pared derribada, por donde se ofician las Misas que se dicen y cantan a Ntra. Sra. del Rosario hermandad de los españoles por cuya causa se sintieron muy agraviados los dichos hermanos... y que la dicha ventana se quedase en el estado en que estaba sin que en ningún tiempo se pudiese hacer otra tribuna en ella ni más obra de la que tiene y que en la dicha capilla se haría bóveda para enterrarse los dichos hermanos... y colocarían la dicha imagen a la pared frontera que sale a la capilla de los naturales" 21.

21 AGN, escribano Pedro López de Malilea, 1638-1639, protocolo 986, fols. 543 r-vta. 
El análisis de este texto arroja los siguientes resultados:

Primero: se abrieron por aquellos años los muros divisorios de las capillas laterales situadas entre las dos puertas laterales de la iglesia y las capillas de Agüero y Aliaga. Esta situación permaneció estacionaria desde entonces hasta la década de 1680 en que se logró abrir el gran crucero nuevo y se cumplió la libre comunicación entre éste y las naves laterales, derribando los dos muros transversales que todavía aparecen dibujados en el plano de Meléndez.

Segundo: no se prosiguió la reforma por las divisiones entre las capillas laterales situadas entre las dos puertas laterales de la iglesia y el muro de los pies. Ellas permanecen todavía cerradas e incomunicadas con la nave central como a principios del siglo XVII. Parece ser que nunca se formuló un plan orgánico integral para reformar el sector de los pies en la iglesia dominicana. La misma ampliación del coro alto, que se estudiará a continuación, resultó una medida inconexa y desintegrada con el desarrollo completo de todo el sector de los pies de la iglesia.

Tercero: la terca oposición de los hermanos veinte y cuatro de la cofradía del Rosario frustró por entonces la apertura del muro transversal que separaba su capilla de la de los Aliaga. Los frailes dominicos tuvieron que acceder a que la cofradía colocara el altar de la Virgen del Rosario en ese muro transversal, en lugar de abrirlo, y que cortaba la prolongación de la nave lateral de la epístola hasta el testero de la iglesia. También se opusieron aquellos veinte y cuatro a que el convento colocara una tribuna o balcón en la ventana abierta en cl. antecoro frente a su capilla del Rosario. Permazece esta ventana actualmente en el mismo estado en que la dejaron por cl concierto citado de 1638 .

Cuarto: la nave lateral del lado del evangelio quedó truncada de un modo similar a la de la epístola. No sabemos si ello se debió a la oposición de alguna cofradía poderosa o al desaliento de los frailes dominicos al no poder continuar las reformas hasta el muro testero. El plano de Meléndez mues- 
tra el estado en que quedó la iglesia por este sector central después de las reformas en las naves laterales. Posteriormente se abrió el crucero tal como lo representa el mismo plano de Meléndez; pero los últimos muros transversales en las naves laterales sólo se pudieron abrir con posterioridad a la publicación de este plano y ello tras largas negociaciones con la intransigente cofradía de Nuestra Señora del Rosario.

La segunda obra importante que influyó en la evolución posterior de la planta de la iglesia dominicana consistió en la fábrica del segundo campanario, concertada con el mismo alarife Antonio Mayordomo, con fecha de 22 de enerc de $1632^{22}$. No se trataba todavía del gran campanario en forma de torre levantado por el alarife Francisco Cano Melgarejo según traza cle fray Diego Maroto, sino de una simple espadaña que venía a sustituir a la precedente más modesta y de materiales débiles. No se describe en el concierto aquella segunda espadaña de Mayordomo, ya que el concierto notarial se remite a la planta y montea diseñada por el obrero mayor àe obras del convento fray Juan García, dominico.

Más importancia que la planta misma tiene ahora el determinar el lugar donde se edificó la espadañı de Antonio Mayordomo. Creo que estaría colocada en la parte exterior del muro del evangelio hasta el límite final de este muro. Así lo inferimos de este detalle anotado en el concierto notarial: en cada esquina del muro lateral de la iglesia existía un pequeño torreón, sin duda similar al que posteriormente dibujaba el grabado de Meléndez sobre la prolongación del coro alto; pues bien, señala el concierto que «torreones y pared ha de ir enrasado como está en la dicha planta». De esta manera, la espadaña de Mayordomo y la gran torre de Cano Melgarejo ccuparon sucesivamente la misma posición en lo que entonces era la esquina de la iglesia. De suyo, la colncación de la de la espadaña no determinaba necesariamente la de la torre posterior que había de sustituirla; sin embargo, por razones

22 AGN, escribano Juan de Valénzuela, 1632, protocolo 1260, fol. 175. Se incluye como Anexo documental, II. 
que no podemos determinar, fray Diego Maroto prefirió colocar su torre en la misma posición en que había estado la segunda espadaña. Esta subordinación del lugar de la torre al de la espadaña frustró el desarrollo de la gran fachada barroca a los pies de la iglesia de Santo Domingo; pues la torre quedó retrasada respecto del muro frontero adelantado que se había formado por la prolongación del coro alto en 1633 . Otro hubiera sido el aspecto frontal que presentara la iglesia de Santo Domingo si Maroto hubiera retrasado la torre hasta alinearla con la nueva fachada del coro alto. Claro que, en tal supuesto, hubiera tenido que levantar otro cubo de torre similar y paralelo en el sector de patio en la otra esquina del coro alto; y acaso también habría tenido que desplazar de algún modo la entrada a la portería del convento dominicano. Lo cierto es que ni en los tiempos de García ni en los de Maroto pensaron los dominicos en prolongar las capillas laterales a los lados del coro para privilegiar la portada a los pies de la iglesia; pues siempre han mantenido como única y principal portada la lateral. Pareciera como que la colocación anómala de la gran torre de Cano Maroto hubiera querido frus-' trar en la iglesia de Santo Domingo la formación de la gran fachada barroca en el muro de los pies que lucen con tanta prestancia San Agustín, San Francisco, la Merced y la catedral, además de las iglesias menores como la de las Trinitarias.

La tercera obra decisiva para el futuro de la iglesia consistió en alargar el coro alto desde la primitiva pared de los pies de la iglesia «hasta el pretil del cementeric». Concertó esta obra el prior del convento con el mismo alarife Antonio Mayordomo por concierto notarial de 14 de febrerc de $1633^{23}$. Se hubiera podido dejar el lugar libre para la fran fachada si en lugar de hacer esa prolongación externa del coro alto, se

23 AGN, escribano Juan de Valenzuela, 1633, protocolo 1694, fol. 214. Se adjunta como Anexo Documental, III. Escribe asI la doctora Barriga: «Un posible concierto para «alargar el coro en los pies de la iglesia hasta el pretil del cementerio (A. San Cristóbal: «El Comerciow, Lima, 2 de diciembre de 1982) no se justificaríaw. Barriga: La iglesia..., pág. 9, /nota 8. Sin embargo, la obra existe desde 1633 hasta ruestros dlas, aunque la doctora Barriga no la represente en su plano de la iglesia: véase el plann en la página 20 de su estudio. 
hubiera edificado un coro bajo y alto dentro de la misma iglesia, como los que edificó el mercedario fray Pedro Galeano en la iglesia de la Merced y en la iglesia del monasterio de Santa Catalina; o también si se hubiera acompañado este cuerpo saliente con sendos cuerpos robustos de torres alineados hasta el mismo pretil del cementerio. Pero como el coro alto alargado quedó solitario y desamparado, no ha producióo otro efecto arquitectónico que el de distorsionar y frustrar el armónico desarrollo de la planta de la iglesia de Santo Domingo en il sector de los pies.

En el concierto notarial no aparece ninguna descripción arquitectónica de la ampliación a realizar en el coro alto, excepto la somera alusión a las bóvedas. Ahora bien, ya que se conserva esta obra en su integridad y sin modificaciones de ningún género, nos basta con acudir a la realidad existente para valorar no tanto su construcción, cuanto lo que ella repercutió en el desarrollo de la planta de la iglesia dominicana. Por lo pronto, se cubrieron dos techumbres superpuesias fuera del perímetro que hasta entonces ocupaba la iglesia: una en forma de bóveda de cañón rebajado en arco carpanel con lunetas a los lados, situada a mitad de la altura de la iglesia, sobre la que asienta el coro alto ampliado; la segunda, que cubriría este nuevo ambiente, sería la prolongación de la cubierta de la nave central hasta el límite del «pretil del cementerio». Nos interesa destacar los siguientes aspectos en relación a la planta de la iglesia:

Primero: sólo se prolongó el coro alto en $\epsilon$ ] sector que corresponde exclusivamente a la nave central de la iglesia; pero no se prolongaron los espacios laterales colocados sobre las primeras capillas laterales. De este modo, el muro de los pies en la iglesia dominicana no forma una línea recta, sino quebrada, más adelantada en la nave central que en las laterales.

Segundo: con esta prolongación, se ganaron dos nuevos ambientes: el sotacoro y el coro alto; pero sólo este último fue incorporado al ámbito interno de la iglesia; mientras que 
el sotacoro quedó como un nártex o atrio externo delante de la antigua portada de los pies. En consecuencia, también se observa la irregularidad de que la nave centrai tiene mayor longitud en el coro alto que en el coro bajo.

Tercero: no se prolongó hacia el interior de la iglesia la bóveda de cañón rebajado ejecutada en la parte externa. La iglesia de Santo Domingo es, pues, la única entre las grandes iglesias conventuales de Lima que carece de un sotacoro abovedado a continuación inmediata del muro de los pies. Hay que reconocer que si se hubiera ejecutado algún trame de bóveda para cubrir el sotacoro en el interior de la iglesia, las últimas capillas laterales habrían quedado taponadas por esa construcción. Es posible que, por tal motivo, la oposición de las cofradías asentadas en esas capillas haya frustrado cualquier plan de prolongar la bóveda del coro bajo dentro de la iglesia. Se cubrió el sotacoro o nártex externo con tres tramos de bóveda de cañón rebajada con lunetas. Pero en lugar de colocar el cañón de la bóveda en sentido longitudinal con la nave central interior, lo colocaron en sentido transversal. Ninguna otra iglesia limeña muestra esta disposición tan anómala, que imposibilita la continuidad del sotacoro con la nave central.

Cuarto: la parte del coro alto primitivo en el interior de la iglesia asienta sobre un piso o plataforma intermedia de maderá. Este coro interno de Santo Domingo constituye actitaltríente el 'urticó 'vestigio que nos queda en Lima de los primitivos coros de las grandes iglesias conventuales, al qute sé afraden aún los cö́ros de las iglesias menores en los monasteriós de las Desćalzaś de San Joseph y de la Santísima Tririjadad. Hasta dondé alcanzá'la 'información de archivo que he fódido acopiar, Ids ptimleros corós conventuales sobre bóve-

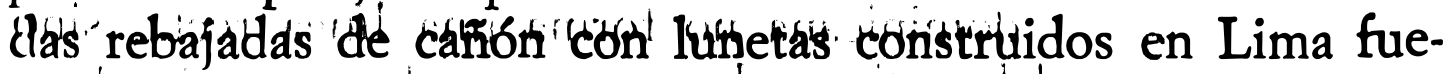
for ' el de la iglesia de' San 'Aguistîn, 'obra del arquitecto Francisco Becerra, concertado el 11 de enero de $1592^{24}$; y los que énstruyb el mercedario fray' Pedro Galeano para la igle-

24 AGN, actibano Diego Martínez, 1592, frotocolo 110, fol, 203. 
sia de la Merced y para la del monasterio de Santa Catalina. A semejanza de ellos se construyó la ampliación externa del coro alto para la iglesia de Santo Domingo, aunque en posición cliferente.

Quinto: con la formación del sotacoro o nártex externo, la primitiva portada de los pies quedó truncada. Antes de iniciarse esta obra existía allí una portada de diseño renacentista, que constaría de dos cuerpos con frontón terminado en una cruz entre pináculos. Pues bien, al derribar la mitad superior del muro de los pies para abrir la prolongación del coro alto y anteponer allí la nueva bóveda transversal del sotacoro externo, se cortó la portada por el segundo cuerpu y parte del primero. Se pueden observar todavía los restos bajos de aquella portada renacentista. Por otra parte, los dominicos no se preocuparon en lo sucesivo de suplir la vieja portada desaparecida por otra nueva antepuesta al muro quebrarlo de los pies en la parte más adelantada en el lindero de la calle. La desvalorización, o mejor desaparición de la portada de los pies, consumada en 1633, impuso la correlativa revalorización de la portada lateral en el muro del evangelio.

Es importante aclarar algunas informaciones acerca de lá portada de la iglesia de Santo Domingo. Resumiendo la obra de Meléndez en la parte pertinente, escribía el padre Domingo Angulo que, entre las obras subsiguientes al terremoto de 1678, el provincial fray Juan de los Ríos «hizo después la portada de la misma iglesia» ${ }^{25}$. El padre Angulo dice claramente «la portada», sin añadir que ella sea la «principal», o que se trate de otra nueva distinta de la lateral que era hasta entonces la única existente en la iglesia. Sin embargo, sobre la base de su información, amplía así la doctora Barriga: «Luego mandó construir (se entiende el mismo fray Juan de los Ríos) la portada principal de la iglesia, la lateral ya existía desde principios del siglo XVI» ${ }^{28}$. Se trata de la misma información acer-

25 Angulo: La Orden..., pág. 215.

26 Barriga: La iglesia..., pág. 13. 
ca de la misma portada mandada hacer por el mismo provincial; pero parece en este segundo comentario que se tratara de otra portada - la principal- distinta de la lateral del siglo XVI. Surge, pues, la pregunta: ¿cuál fue la portada mandada construir por el padre Juan de los Ríos después dn 1678? Evidentemente no puede tratarse de una portada principal distinta de la lateral y que hubiera estado situada en el muro de los pies, ya que allí está la única puerta externa sin portada. Las razones son, porque la prolongación del coro alto impide radicalmente la formación de alguna portada en este sector, que permanece desnudo y sin adorno arquitectónico desde 1633; además de que el grabado de Meléndez publicado inmediatamente después de las obras realizadas por Fray Juan de los Ríos hacia 1681, no muestra ninguna portada en el muro de los pies.

En cambio, el mismo grabado de Meléndez con el frente de la iglesia y convento de Santo Domingo representa muy claramente la portada lateral con dos cuerpos y tres calles en cada uno de ellos. Esta portada, reproducida por Meléndez, constituye la ampliación de otra renacentista inicial, fácilmente reconocible, porque la calle central del segundo cuerpo tiene menor anchura que la calle inferior del primer cuerpo, como era usual en las portadas virreinales renacentistas hasta principios del siglo XVII, además de conservar el entablamento corrido sobre el primer cuerpo. Esta portada lateral no podía tener dos cuerpos de tres calles cuando fue labrada en el siglo XVI, por la sencilla razón de que entonces no estaba en uso el diseño barroco de la cuadrícula regular completa. Por consiguiente, deducimos que las dos calles laterale's del segunćo cuerpo, que por lo demás son más anchas que las calles similares del primer cuerpo, fueron añadidas posteriormente curante la etapa barroca. Esto significa que la portada promo-vida por el provincial fray Juan de los Ríos entre 1678 y 1681 no fue una portada nueva, que no existe en la iglesia dominicana; sino que consistió en añadir las calles laterales en el segundo cuerpo a la portada del muro del evangelio para trans- 
formar la primitiva portada renancentista allí existente en una portada-retablo barroca de dos cuerpos y tres calles, que es la representada por el grabado de Meléndez. A partir de la ampliación del coro alto en 1633, la iglesia de Santo Domingo cuenta únicamente con la portada lateral del lado del evangelio. Esta portada ha pasado sucesivamente por $\epsilon$ stos momentos estilísticos:

1. La portada inicial de diseño renacentista;

2. La portada-retablo metamorfoseada en barroco por fray Juan de los Ríos después de 1678;

3. La portada actual, fruto de la vandálica deformación de la iglesia perpetrada por Matías Maestro.

Las modificaciones que se efectuaron en la iglesia de Santo Domingo durante el primer tercio del siglo XVII no obedecieron a un plan integral de conjunto, similar por ejemplo al que se ejecutó gradualmente en la iglesia de la Merced para lograr su reconversión a planta basilical. Sólo durante el último tercio del siglo XVII se emprendieron reformas más amplias y orgánicas de la planta; pero esta vez no en el sector de los pies de la iglesia, sino en el de cabecera. Se trataba de resolver definitivamente el viejo problema de la pequeña capilla mayor señalado por los cronistas de comienzos del siglo XVII.

Con ocasión del terremoto de 1678 decidieron los dominicos modificar la planta de la iglesia. Las reformas consistieron en ampliar el espacio delantero introduciendo el crucero; y en abrir al tránsito los últimos muros cerrados entre el mismo crucero y las dos naves laterales, con lo que se consumaría la desprivatización de las capillas. La primera reforma era exclusivamente arquitectónica; mientras que la segunda, adeInás de sus implicaciones sobre la planta de la iglesia, incidía en el fuero jurídico de la propiedad privada mantenida por algunas familias y cofradías sobre las capillas que: eran su lugar de enterramiento y devoción.

Tomo XLIX 
En el latísimo concierto notarial firmado en 1683 leemos estas palabras ilustradoras:

"... y haciendo otro retablo en toda perfección según como lo está el que al presente tienen que es de los mejores de la iglesia a costa del dicho Convento ha de hacer conación a la dicha Ccifradía de todo el sitio que por haberse alargado la iglesia se ha aumentado en la capilla de San Gerónimo para que en él puedan ampliar los dichos veinte y cuatros la bóveda que al presente tienen y acercarla al dicho altar de San Gerónimo en el cual también han de poder hacer camarín por la parte adentro del dicho Convento para que se pueda vestir la imagen santísima de Nuestra Señora con la decencia debida y que si acercan la bóveda de los veinte y cuatros al altar de la Virgen dándoles para ello cl Convento dicho sitio ha de dejar al Convento la dicha Cofradía la bóveda que hoy tiene de los veinte y cuatros..." ${ }^{27}$.

Tanto en el concierto notarial de 1683 como en el de 1684 se menciona explícitamente que se ba alargado, y se ba ampliado la iglesia del Rosario. Esta ampliación sc realizó derribando toda la parte de la iglesia comprendida entre el muro frontero de las dos capillas de Agüero y de Aliaga hasta el presbiterio, y en edificar el nuevo perímetro de la iglesia en la cabecera, con una capilla mayor más profunda que la anterior; y también adelantando las dos mencionadas capillas con una anchura igual a la de la nave central de la iglesia, de tal manera que se pudo formar el ancho crucero que hoy contemplamos; y se pudiera cubrir su parte central con la airosa cúpula de cedro y yeso. Los dos conciertos notariales localizan con toda exactitud esta ampliación, pues señalan que ambas capillas han ganado un espacio entre sus primitivas bóvedas o criptas sepulcrales y el nuevo muro al que quedaron adosados sus respectivos retablos; este espacio añadido es el que había permitido formar el nuevo crucero.

Las reformas anotadas se habían realizado a partir de 1678 , y han sido incorporadas en el plano publicado por Me-

27 AGN, escribano Pedro Pérez Landero, 1683, protocolo 1479, fol. 530 vto. Es un concierto tripartito de 36 folios entre el convento, la cofradla del Rosario y los Aliaga. Los mayordomos del Rosario adquirieron el derecho a tener en su capilla bóveda sepulcral por concierto notarial de 7 de noviembre de 1661, formado con el prior del convento fray Do mingo de Cabrera: AGN, escribano Martín de Ochandiano, 1661, protocolo 1298, fol. 495. 
léndez. Hay que recordar muy claramente que la apertura de los muros transversales entre las capillas que se observa en el plano de Meléndez no procede de esta etapa posterior a 1678, pues fue realizada durante la década de 1630 , como ya se ha estudiado antes. Después de leer detenidamente los conciertos notariales de 1683 y 1684 , podemos sostener con toda certeza que el plano de Meléndez no corresponde a la planta inicial de la iglesia de Santo Domingo que conocieron Cobo y Lizárraga, pues incorpora la apertura de las naves laterales hechas antes del concierto de 1638 y también la construcción del crucero y nueva capilla mayor realizada a partir de 1678 . Merece la pena leer atentamente el plano de Meléndez, pues en él encontramos las siguientes innovaciones, respecto de la planta de principios del siglo XVII:

a) aparece ampliado el presbiterio con muro plano testero en la cabecera de la iglesia;

b) la capilla de'Aliaga, con su altar de San Jerónimo, y la de Agüero, con el altar de Crucifijo donde estaba colocada Santa Rosa, han perdido la forma de capillas-hornacinas cerradas que tuvieran inicialmente y han pasado a formar parte del espacio más amplio del crucero nuevo. Figura también señalada la media naranja en el centro del crucero. Todavía permanece señalado como altar de Santa Rosa el de la capilla de Agüero en el lado del evangelio.

c) se distingue perfectamente en el plano la apertura de la comunicación entre las capillas de las naves laterales, con la única y notoria excepción de los muros que incomunican el crucero con las capillas de Nuestra Señora del Rosario y de San Juan Bautista. La apertura de aquellas capillas laterales data de la década de 1630 , como se ha indicado; la apertura de los dos últimos muros transversales constituyó el enojoso problema juídico que se resolvió mediante los largos conciertos notariales de 1683 y 1684 . 
Desde luego, el plano de Meléndez no llegó a incorporar la apertura de los dos últimos muros transversales, porque sólo alcanzó a historiar las obras ejecutadas durante el provincialato del padre fray Juan de los Rííos, que terminó el 24 de julio de 1681. Dice así el mismo Meléndez en su obra: «En lo restante de su provincialato concluyó nuestro Provincial las obras que quedan dichas, y acabado gloriosamente su oficio a 24 de julio de 1681, no sabemos todavía en Roma el que le ha sucedido, si viniere la noticia a tiempo en que se pueda estampar, lo haremos al final de este quinto libro y tercer tomo» ${ }^{28}$. Sabemos también que estas obras, incorporadas en el plano de Meléndez, se ejecutaron con posterioridad al terremoto de 17 de julio de 1678 , según refiere también el mismo Meléndez ${ }^{20}$.

Por si quedara alguna duda acerca de todo este prolongado proceso de reconversiones en la iglesia del Rosario, transcribimos aquí el largo fragmento en que Melérảez describe las obras realizadas en la iglesia por el provincial Juan de los Ríos. Dice así el tomo III del cronista dominico:

\begin{abstract}
"Había muchos días que se temía ruina en la Capilla Mayor porque de sus bóvedas de ladrillo y cal había caído un pedazo y se deseaba dar orden como asegurarlo todo; y el Provincial pensando con una obra ocurrir a las dos necesidades de remediar el daño que amenazaba la $\mathrm{Ca}$ pilla Mayor y hacer capilla al cuerpo de Santa Rosa, habido consejo con los Padres más sraves del Convento, en que hubo diferentes pareceres conforme al humor de cada uno, derrib6 la Capilla mayor amtions y en su mismo sitto, exteondiéndiose algo miss por uno y otro lado, emprear di6 animosamento la fébrita de un cucero que ya le tlene acabado y remata en una cúpula o media naranja bellísima adornada por dentro de Santos de la Orden hechos de modia talla, de madera de cedro, que representan una gran majestad. Al mismo tiempo trató con el mayorazgo de los caballeros Agüeros patrones de la capilla de su apellido que (como se ha dicho ya) es la inmediata al lado del evangelio detrás del altar mayor, que consintiese en que en su altar se pusieso colocado el cuerpo santo de la Virgen Santa Rosa, obligándose su Paternidad a
\end{abstract}

28 Meléndez: Tesoros verdaderos..., t. III, Roma, 1682, pág. 846. La obra de Meléndez termina con el gobierno del P. Juan de los Rlos como Provincial.

29 Ibidem, pág. 811. 
hacer un rico retablo al altar en que se colocase por remate la imagen del Crucifijo que sus devotos Progenitores tenían colocado en el altar de la capilla vieja; pactando que en la capilla y retablo se pusiesen las armas de los Agüeros y tuviesers su sepultura inmediata a la peana del altar en medio de la capilla; pero con condición de que colocado en su altar el cuerpo de Santa Rosa no adquiriesen ningún derecho ni posesión sobre las sagradas reliquias, sino que pudiese el Convento todas las veces que le pareciese convenir sacar de allí el cuerpo santo y ponerlo en la parte que quisiere" ${ }^{30}$.

Si el padre Domingo Angulo hubiese concordado este largo texto del tomo III de Meléndez con los conciertos notariales de 1683 y 1684 , no habría embrollado inneresariamente la sencilla historia de la reconversión de la planta de la iglesia de Santo Domingo. Pero debemos añadir que carece de validez la afirmación suya en que atribuye las reformas al gobierno prioral de fray Diego Morato en 1681-1684 ${ }^{31}$; es decir, después de publicada la obra de Meléndez y su plano del convento e iglesia del Rosario. Esta opinión de Angulo es la que ha confundido a Wethey, que sólo sobre esa base pudo sostener que la planta de la iglesia había permanecido inalterada desde sus orígenes hasta el plano de Meléndez en 1681. Ahora bien, tanto el largo texto citado como los conciertos notariales de 1683 y 1684 desvirtúan las opiniones de Angulo y Wethey, ya que en ellos se menciona explícitamente que la iglesia se ba ampliado, y se ba alargado, además de que ello se hizo «extendiéndose algo más por uno y otro lado». Lo único que se realizó durante el gobierno prioral del padre maestro Diego Morato fue la apertura de aquellos dos muros transversales que todavía permanecían cerrados entre el crucero y las capillas de San Juan Bautista y del Rosario, que es lo que atestiguan los conciertos de 1683 y 1684; pero esto no constituye ninguna ampliación o modificación estructural de la planta, sino una simple reforma interna para la libre comunicación.

El cronista dominicano Meléndez afirmaba que la planta de la iglesia del Rosario «formóse de tres partes: capilla ma-

30 Ibidem, págs. 810-811.

31 Angulo: La iglesia..., pág. 222.

Tomo XLIX 
yor, cuerpo que llaman de la iglesia, y la gran pieza del coro» ${ }^{32}$. $Y$ añade seguidamente la conformación de la capilla mayor que por entonces comprendía ya «el presbiterio, crucero y dos capillas laterales», a saber: la de los Aliaga, en el lado de la epístola, y la de los Agüero, en el lado del evangelio. Tomando las medidas señaladas por el mismo Meléndez, notamos que el crucero tenía después de las reformas treinta y seis varas de largo, y que su ancho era de quince varas como el ancho de la nave central, para formar en el centio un cuadrado perfecto sobre el que se eleva la circunferencia de la media naranja. Evidentemente, con las nuevas dimensiones que Meléndez atribuye a la capilla mayor ampliada, había desaparecido el fundamento de la queja expresada por los cronistas Cobo y Lizárraga, según los cuales la capilla mayor «para tan grande iglesia es tenida por pequeña». Aunque no conocemos las dimensiones de la iglesia del Rosario a principios del siglo XVII, sospechamos que la cabecera terminaría en la línea de separación del actual crucero nuevo; de tal modo que, después de 1678 se añadió a la planta todo el espacio del presbiterio actual, además de abrirse el nuevo crucero sobre el solar de las antiguas capillas-hornacinas cerradas de los Aliaga y Agüero, con un espacio adicional que es donde se trasladaron los retablos de estas viejas capillas desaparecidas como tales. Este espacio adicional incorporado en la nueva planta va a ser materia de negociación en los conciertos notariales de 1683 y 1684; pues aunque amplió el espacio de las dos capillas mencionadas, sin embargo no tra propiedad de éstas, sino del convento de Santo Domingo que había cedido la parte correspondiente de su propio solar para abrir el nuevo crucero.

Con posterioridad al levantamiento del plano de $\mathrm{Me}$ léndez, pero con anterioridad al día 7 de septiembre de 1683, en que se concertó el convenio con el mayorazgo de Aliaga, ya se había abierto el único muro transversal que permanecía

32 Melendez: Tesoros..., t. I, pág. 54. 
cerrado en la nave del evangelio, entre la capilla de San Juan Bautista y el crucero. Sólo quedaba pendiente de abrir el muro que cerraba la comunicación entre el crucero y la capilla de Nuestra Señora del Rosario. Tanto por el plano de Meléndez como por las descripciones de Lizárraga y de Cobo sabemos que la famosa capilla del Rosario estaba situada antes de 1684 en la nave lateral de la epístola, entre la capilla de los Aliaga ${ }^{33}$ y la de las Reliquias, que fue incorporada a ella desde 1608. La apertura del muro entre la capilla de San Juan Bautista y el crucero está confirmada por este fragmento del concierto de 1683:

Lem:

"que por cuanto por haberse reedificado la iglesia del dicho Convento y abiértose el arco de la parto donde estaba el retablo de San Juan Bautista para que tuviera correspondencia y perfección de la obra dando paso a la capilla mayor, es necesario que se abra el arco de la capilla de Ntra. Sra. del Rosario donde está la santa imagen colocándola en otra parte que esté en la veneración debida se acordó que fuese la de San Gerónimo que pertenece al mayorazgo ..." B4.

Tratando de abrirse este último muro transversal, la poderosa cofradía del Rosario no pudo ofrecer resistencia a ello. Sin embargo, el concierto notarial comprometió a terceras partes hasta conseguir un lugar decoroso donde colocar la imagen de la Virgen del Rosario, al haber quedado abierta su antigua capilla. No sabemos cómo pudieron los frarles dominicos lograr el consentimiento de las poderosas familias de los Agüeros y los Aliagas para que cooperasen en la apertura de sus capillas-hornacinas, que era necesaria para formar el nuevo crucero. Los conquistadores Aliaga y Agüero habían comprado tales capillas y habían establecido en ellas sus sepulturas familiares, además de las consabidas capellanías. La facilidad con que se plegaron a la transformación de sus capillas de propiedad feudal significa un cambio fundamental en las prácticas religiosas. Las capillas privadas dentro de las iglesias

33 Lizárraga: Descripción..., pág. 32; Cobo: Historia..., pág. 238.

34 AGN, escribano Pedro Pérez Landero, 1683, protocolo 1479, fols. 510 r-vta. 
virreinales reflejaban todavía el poder feudal de las clases dominantes, en este caso el poder de dos de los más destacados conquistadores del Perú. Un siglo después de fundadas estas capillas, en Santo Domingo prevalecía el poder institucional de las cofradías sobre el de las personas o las familias. Si los dominicos hubieran pretendido abrir el crucero de la iglesia un siglo antes a costa de estas mismas capillas de Agüero y Aliaga, se habrían enfrentado a la invencible resistencia que encontró el cabildo metropolitano de la catedral frente a un problema semejante; y posiblemente se habríarı tenido que contentar con abrir el crucero de la iglesia en otro lugar, como sucedió en la catedral de Lima. Pero en 1683 la oposición provenía no de las personas feudales, sino de la poderosísima cofradía del Rosario; y ellos fueron los que finalmente impusieron sus condiciones para derribar el último muro transversal entre la capilla y el nuevo crucero.

Para resolver el problema del traslado del retablo e imagen del Rosario se acordó primeramente un concierto notarial tripartito entre el prior de los dominicos, fray Diego Morato, los mayordomos de la cofradía del Rosario y el maestre de campo don Juan de Aliaga, por el cual cada uno otorgaba a los demás y recibía de ellos algunos beneficios: la cofradía podía trasladar su retablo e imagen a la capilla ampliada de los Aliaga, y dejaba expedito el lugar para abrir el arco que faltaba entre la capilla y el crucero, así como también entregaba al convento su antigua cripta sepulcral; y recibía en compensación el espacio que se había ampliado entre la antigua capilla de los Aliaga y el nuevo muro lateral del crucero, para hacer en dicho sitio nueva bóveda sepulcral. El mayorazgo de Aliaga cedía su altar y capilla para acoger la imagen de Nuestra Señora del Rosario, a cambio de lo cual ingresaría como uno de los hermanos veinte y cuatro mayordomos de la cofradía; pero exigía mantener el retrato del segoviano don Gerónimo de Aliaga, fundador de la capilla. Para ilustración ofrecemos este fragmento del larguísimo concierto notarial: 
"Que tiene por muy acertado el que se abra el arco cie la capilla en que está el retablo de Nuestra Señora del Rosario y que en el de San Gerónimo se ponga el dicho retablo de Nuestra Señora pues en esto se le hace bien al dicho Mayorazgo del dicho Maestre de campo don Juan de Aliaga por estar muy pobre y las rentas decaídas y que haciéndose el retablo... y en el dicho retablo se ponga el del Señor San Gerónimo para memoria del Patronato que en ella está asignado y así mismo le parece muy acertado el que sea uno del Mayorazgo veinte y cuatro de la dicha Cofradía" "Y así mismo es condición que desde luego el dicho Convento ha de hacer donación a la dicha Cofradía de todo el sitio que por haberse alarzado la iglesia se ha aumentado en la capilla de San Gerónimo para que en él puedan ampliar los dichos veinte y cuatros la bóveda que al presente tienen y ecercarla al dicho altar de San Gerónimo en el cual también han de poder hacer camarín por la parte adentro del dicho Convento para que se pueda vestir la Imagen Santísima de Nuestra Señora con la decencia debida" ${ }^{36}$.

A los pocos meses cambiaron de opinión, pues les pareció más honroso colocar la imagen de La Virgen del Rosarío en la capilla del Santo Crucifijo, patronato de los Agüero, también en el nuevo crucero, pero al lado del evangelio, donde estaba puesta la imagen y cuerpo de Santa Rosa de Lima. Reiteraron otro larguísimo concierto notarial, pero esta vez con cuatro contratantes, pues a los tres antes mencionados se unió don Joseph de Agüero, regidor de la ciudad. Establecieron las mismas condiciones, suplantando en las anteriores a don Juan de Aliaga y Sotomayor por el nuevo concertante don Joseph de Agüero. Sólo se añaden dos condiciones nuevas: se 1,ará otro retablo para Nuestra Señora del Rosario con su camarín, el que desde entonces ocupa el lugar actual; y el retablo de Santa Rosa pasará a la capilla de los Aliaga, que es el lugar que mantiene hasta el día de hoy. Dice así el nuevo concierto notarial:

"que por haberse ampliado dicha capellanía y ser necesario adornarla con retablo decente y correspondiente a los que se han puesto en el crucero de dicha iglesia se convino con los religiosos de ella en que

35 Ibldem, fol. 523.

36 Ibldem, fols. 534 r-vta. 
se colocase en su capilla la Santa Rosa y se la hiciese tabernáculo poniéndose en él la efigie del Santo Cristo Crucificado con que se hizo la fundación y dedicación de dicha capilla y es así que por los mismos motivos había consentido el maestre de Campo don Juan de Aliaga Sotomayor, dueño y patrono de la capilla colateral que fundaran sus antepasados, en que se pusiese en ella la imagen de Nuestra Señora del Rosario, se le hiciese tabcrnáculo que la adornase quedando en ella la efigie de San Gerónimo en memoria de su primera dedicación y fundación y hechos estos pactos se ha reconocido que la capilla del suplicante está en lugar más decente al lado del evangelio la imagen de Nuestra Señora del Rosario pasando a la del dicho don Juan de Aliaga Sotomayor el retablo e imagen de la Santa Rosa" ${ }^{37}$.

Creemos que el retablo de Santa Rosa, trasladado desde el lado del evangelio hacia el lugar de la capilla de Aliaga, en el mismo crucero pero al lado de la epístola, era el que había sido concertado por fray Diego Maroto, ;eligioso lego del Orden de Predicadores y maestro mayor de fábricas reales, con Diego de Aguirre para ponerlo en el crucero de la capilla mayor, por el precio ds 3.800 pesos de a ocho reales, por concierto notarial de fecha 6 de octubre de $1681^{38}$.

La poderosa cofradía del Rosario había logrado por fin acomodar su altar e imagen en el lugar más amplio y prestigiado litúrgicamente de la iglesia del convento de Santo Domingo, invadiendo incluso el lugar que era propiedad de una de las familias más influyentes de la conquista del Perú. Satisfechos los mayordomos de tan notoria localización para su cofradía, se aprestaron a cumplir con generosidad los compromisos concertados. Primeramente convinieron con el maestro albañil Francisco Javier Domínguez la construcción de dos bóvedas sepulcrales en la nueva capilla de Nuestra Señora del Rosario, con fecha 27 de enero de $1685^{39}$. Es necesario pre-

37 AGN, escribano Pedro Pérez Landero, 1684, protocolo 1480, fols. 461.541; el texto en el folio 538 .

38 AGN, escribano Alonso Martín Palacios, protocolo 1404, fol. 2073. El retablo llevaría ocho columnas de cedro macizas «salomónicas emparradas de hoja». Dice también «y mejorando el dicho retablo al que está, comenzado enfrente del Santo Cristo de mármol».

39 AGN, escribano Pedro Pérez Landero, 1685, protocolo 1482, fol. 113. vto. El maestro Francisco Javier Domínguez levantó años antes en Pisco la iglesia mayor y la del Señor San 
cisar que este concierto notarial no se refiere a la capilla antigua del Rosario, es decir a la que Lizárraga y Meléndez señalaban en la nave de la epístola a continuación de la capilla àe los Aliaga, sino a la nueva capilla trasladada al lado del evangelio en el crucero, en el altar de los Agüero, con el Santo Crucifijo. Esas dos bóvedas sepulcrales tenían la mayor 8 varas de largo, 6 de ancho y 3 varas y media de profundidad «de la solería menor abajo»; y la bóveda menor destinada a los Agüero sólo tendría 3 varas de ancho, 3,5 de largo y se correría por debajo del altar mayor nuevo. Se concertaron las obras en 1.500 pesos de a ocho reales; y tendrían que quedar a satisfacción del dominico fray Diego Maroto.

En cuanto al nuevo retablo para la flamante capilla del Rosario, también se encargó el ensamblador Diego de Aguirre, con fecha 14 de enero de 1684, por la elevada cantidad de 11.000 pesos de a ocho reales. En el concierto se especifica que «se ha de poner en la capilla en que está el de la Santa Rosa al lado del evangelio... llenando con él todo el testero en el ancho y alto y a espaldas de él en el hueco que quedase se ha de formar el camarín que cupiese con su escalera de madera encajonada para vestir a la Santísima Virgen María Santísima Nuestra Señora del Rosario con sus puertas y la escalera lo más suave que se pudiera hacer en su subida» ${ }^{40}$. Esto indica uue todavía no se hizo el camarín a la manera de una habitación y en material firme de construcción, como se había concertado en 1683 y como finalmente se realizaría con la deco-

Francisco concertándose por 20 pesos diarios y los materiales de la obra: AGN, escribano Juan de Casas y Morales, 1676, protocolo 278, fol. 661. El 18 de abril de 1678 otorgó carta de pago por 1.000 pesos a cuenta de los reparos en las casas del maestre de campo don Alonso de Ortcga y Robles: AGN, escribano Nicolás García, 1679, protocolo 720, fol. 173. El 6 de junio de 1679 se concertó con el provincial de La Merced para hacer el Noviciado en e': convento de la Merced de Lima, a satisfacción de fray Cristóbal Caballero: AGN, escribano Nicolás Garcla, 1679, protocolo 720, fol. 253. El 11 de agosto de 1685 se concertó con los mayordomos de la Cofradía de Nuestra Señora de los pardos en el convento de Santo Domingo para hacer una bóveda sepulcral y un pozo para osario ude la forma y manera y tamaño de la que está hecha en la capilla y bóveda a donde ahora se pasa a Nuestra Señora del Rosario de la capilla de los Agüero». AGN, escribano Francisco Moscoso, 1684-1685, protocolo 1167, fol. 51 .

40 AGN, escribano Pedro Pérez Landero, 1684, protocolo 1480, fol. 69. 
ración de José del Pozo a principios del siglo XIX. El ensamblador Diego de Aguirre cumplió con entregar el retablo terminado en blanco. Los rumbosos mayordomos del Rosario concertaron posteriormente con el maestro doradcr Juan Díez de Gamboa el dorado del retablo por la cantidad de 8.000 pesus, según concierto notarial firmado el día 22 de diciembre de $1685^{41}$.

Algunas dudas debieron albergar todavía los mayordomos de la cofradía del Rosario después de tantas modificaciones y conciertos notariales pues se reservaron siempre el derecho de retornar a su antigua capilla y de cerrar de nuevo la nave lateral de la epístola ${ }^{2}$; pero a lo que se sepa, touavía no ha habido lugar a ello.

\section{ConClusión}

Podemos compendiar la secuencia del proceso histórico de la reconversión de la planta en la iglesia del convento de Santo Domingo de Lima en los siguientes momentos fundamentales:

1.-La planta gótico-isabelina sin crucero, que constaba de una nave alargada separada de la capilla mayor por el arco toral, y tenía dos series de capillas-hornacinas cerradas e incomunicadas entre sí.

2.-La apertura del muro divisorio entre la capilla del Rosario y la de las Reliquias, en la nave de la epístola en 1608.

41 AGN, escribano Pedro PGrez Landero, 1685, protocolo 1485, fols. 2733 vto. y ss.

42 ay caso que se le ponga o pretenda quitar saldrá a voz y defensa el dicho Convento y por el Prior actual y los que sucedieren luego que se le haga saber en cualquier estado que el tal pleito o pleitos estén y los seguirán por todo slos grados e instancias a su propia costa hasta les dejar y que queden en quieta y pacifica posesión y si asi no lo hicieren o sanear no se lo pudieren les restituirán la dicha capilla de Nuestra Señora del Rosario volviendo a cerrar el dicho arco y haciendo otro retablo en toda perfección y según y como lo está el que al presente tienen que es de los mejores de la iglesia a costa del dicho Convento», AGN, escribano Pedro Pérez Landero, 1683, protocolo 1479, fol. 534r. 
3.-La prolongación del coro alto hasta el pretil del cementerio, realizada por el alarife Antonio Mayordome en 1633.

4.- - La apertura de los muros divisorios entre las capillashornacinas de las dos naves laterales, cxcepto el que separaba la capilla del Rosario y la de Aliaga, y el que separaba la capilla de San Juan Bautista y la de Agüero, hasta 1638.

5.- La construcción de la capilla mayor ampliada y del crucero, ocupando este las capillas-hoinacinas viejas de Aliaga y Agüero, por iniciativa del provincial fray Juan de los Ríos, entre 1678 y 1681.

6.- La apertura de los muros divisorios entre las capillas de San Juan Bautista y el crucero y entre la capilla del Rosario y el crucero, por iniciativa del prior p. maestro Diego Morato en 1683 y 1684, después de publicado el plano de Meléndez.

Antonio San Cristóbal 


\section{ANEXOS DOCUMENTALES}

\section{I \\ CONCIERTO: GIL GOMEZ CON ANTONIO MAYORDOMO \\ PARA EL ARCO DE LA CAPILLA DEL ROSARIO EN SANTO DOMINGO}

Sepan cuantos esta carta vieren como nos Gil Gómez mayordomo de la cofradía de Ntra. Sra. del Rosario fundada en el convento de Santo Doningo de esta ciudad de los Reyes del Perú y Antonio Mayordomo albañil residente en ella, otorgamos y conocemos que somos convenidos y concertados de hacer la obra por la orden y piecios en la forma siguiente:

Primeramente, que yo el dicho Antonio Mayordomo me obligo de hacer y que haré un arco en la capilla de Ntra. Sra. del Rosario para la parte de la capilla de Las Reliquias y el dicho arco ha de hacer la montea tal y de la manera y del tamaño del arco que está en la capilla de Ntra. Señora para la parte del cuerpo de la iglesia el cual dicho arco que he de hacer ha de tener el mismo ancho y ha de ser con la misma labor por la parte de la capilla de Ntra. Señora que sstá hecho el dicho arco o sea la del cuerpo de la iglesia y por la otra parte del arco que he de hacer se ha de guardar la orden que lleva el mismo arco y por la parte de abajo de la mocheta del arco ha de llevar la talla que tiene el dicho arco referido y ha de tener el mismo ancho para abajo de manera que los tres arcos estén a un alto y a una montea y ha de ser con sus pilastras la una arrimada al pilar toral y la otra arrimada a la pared del claustro y las pilastras han de ser con la misma labor y talla que está dicho revolviendo y resaltando los basamentos por la orden que requiere para la buena labor y las pilastras han de ser con artesones cerrados con sus florones de yesería, todo curioso y perfecto y he do cerrar cste arco con las formas de las capillas el trasdós del arco asegurando las formas de manera que no corran ningún detrimento crucero ni forma ni r ampante y se entiende y es condición que este dicho arco le he de cerrar sobre la pared que es donde hoy está que ha de servir de cimbra volviendo como me obligo a macizar lo que picare y cavare de la dicha pared hasta que de todo punto el dicho arco esté cerricic'o seco $y^{\prime}$ embebicio.

* AGN, escribano Cristóbal Aguilar Mendieta, 1607-1608, protocolo 50, folio 490 vta. 
Más me obligo de abrir una ventana que corresponda a la capilla de las Reliquias como la que corresnonds a la capilla de Ntra. Sra. del Rosario si pareciere que conviene ha de ser de otra manera. Más me obligo que he de solar la capilla de las Reliquias conforme está solada la capilla de Ntra. Sra. del Rosario todo a nivel y he poner los azulejos que se han de rodear en una conformidad como está la capilla de Ntra. Sra. del Rosario resaltando por los pilares por la parte de dentro de suerte que es a mi cargo ponerlo todo en perfección. Y es á mi cargo de poner la madera para las cimbras y demás pertrechos y he de solar el aposento que está en la capilla de San Juan de Letrán de ladrillo y afijar la puerta y así he de hacer el dicho arco en la dicha forma de manera que esta obra esté acabada en perfección y conforme arte, pincelada cabayada y enlustrada por si se quisiere dorar con su talla sin que le falte cosa alguna de suerte que esté a vista de oficiales y maestros peritos en el arte y a contento del Provincial y convento y de los Mayordomos de la dicha cofradía para cuya labor el dicho Gil Gómez y los mayordomos que fueren de la dicha cofradía han do ser obligados a dar los materiales que se entiende cal y arena y ladrillos yeso clavos para forrar la tabla porque lo demás los peones y oficiales los he de poner yo a mi costa la cual Jicha obra he de hacer bien acabada y perfecta y fuerte de manera que no tenga ningún daño ni riesgo que sea causa por mi descuido o negligencia so pena de pagar los daños que sobro ello se recrecieren demás de que ha de ser a vista de oficiales puestos por ambas partes para que declaren si está perfectamente acabada para que visto si viniere algún daño que remediarse se remedie y torne a hacer de nuevo a mi costa por la cual dicha obra el dicho mayordomo que es o fuere me ha de dar y pagar ochocientos pesos corrientes de a ocho reales el peso, pagados en la forma que irá declarado con lo cual me satisfago y contento por la dicha obra la cual empezaré a hacer cada vez y cuando el dicho mayordomo ( 1 los que lo fueren me empezaren a entregar y dieren los materiales y no tengo de alzar la mano de la dicha obra hasta dejarla acabada la cual dicha obra tengo de dar acabada dentro de tres meses de como la empezare no faltándome los materiales y si teniéndolos no acabare la dicha obra o la dejare de la mano el dicho mayordomo o los que fueren puedan buscar otros oficiales y concertarse con ellos para hacer la dicha obra y la acaben o prosigan hasta que lo acabe y ics pagar por los pesos que ellos se concertaren y si ios tales pesos montaren más des lo que están obligados a dar los pagaré luego que conste de la paga de lo que más montare por su juramento en que queda desde luego diferido la prueba de ello sin que sea necesario otra diligencia porque de ello les relevo y si acabare la dicha obra en el dicho tiempo por ella se me ha de pagar los dichos ochocientos pesos corrientes de a ocho reales los cuales se me han de pagar en esta manera: cada sábado desde el principio que se empezare la dicha obra se me han de dar y entregar cincuenta pesos de a ocho reales hasta en cantidad de quinientos 
pesos para pagar los oficiales y peones cada sábado y no menos porque los c'emás pesos restantes cumplimiento a los dichos ochocientos pesos se me han de pagar luego la dicha obra esté acabada en toda perfección y a contento de las personas atrás referidas para cuya firmeza y cumplimiento obligo mi persona y bienes habidos y por haber y yo el dicho Gil G6mez que soy presente $y$ en nombre de la dicha cofradía acepto esta escritura a cuyos bienes obligo ...(siguen cláusulas notariales de obligación) y lo otorgamos en la dicha ciudad de los Reyes en sicte días del mes de noviembre de mil y seiscientos y ocho años y los otorgantes, que yo el escribano doy fo que conozco, lo firmaron de sus nombres siendo a ello presentes por testigos Diego Nieto Maldonado y Juan Melgarejo y Joseph Gómez presbítero.

Antonio Mayordomo

Gil G6mez

\author{
ante $\mathbf{m i}$ \\ Juan de Zamudio \\ escribano de Su Majestad
}

\title{
CONCIERTO: ANTONIO MAYORDOMO CON EL CONVENTO DE SANTO DOMINGO PARA EL CAMPANARIO•
}

Sepan cuantos esta carta vieren como yo, Antonio Mayordomo maestro de albañilería residente en esta ciudad de los Reyes del Perú, otorgo que soy convenido y concertado y por la presente me concierto con Su Paternidad del Padre Maestro Fray Gabriel de Zárate, Prior Provincial de la Orden de Predicadores de esta Provincia del Perb́, en tal manera que mo obligo do hacer para el convento de la dicha Orden de esa dicha ciudad un campanario del modelo orden y forma que se contiene en la traza que en esta razón tiene hecha el hermano Fray Juan García, religioso de la dicha Orden, la cual está firmada de mi nombre sin exceder de ella en manera alguna kaciendo todo el dicho campanario de cal y ladrillo y con las condiciones $y$ declaraciones siguientes:

Primeramente, que el cimiento ha de ser de piedra del río y arena y ha de subir hasta la basa una vara de alto de piedra del cerro y mampostería con las esquinas de las pilastras hasta la dicha basa de piedra labrada.

Item, la basa ha de correr de ladrillo por todas las ... (falta en el original

* AGN, escribano Juan de Valenzuela, 1632, protocolo 1260, folio 75. 
una palabra) de la pared de suerte que torreones y pared ha de ir enrasado como está en la dicha traza con toảo lo demás que contiene.

Item, el pilar de enmedio ha de haber un caracol que venga a salir debajo de la campana de en medio con la puerta a entrambas partes como se contiene en la dicha traza.

Item, he de quitar las campanas y ponerlas en la pared del coro de suerte que puedan servir y después volverlas a poner en sus arcos todo a mi costa.

Item, tengo de derribar el campanario que está hecho a mi costa quedándome con el ripio adobes y tierra con obligación que hago de dar para unas celdas que se han de hacer en el patio de la carpintería los adóoes necesarios.

Item, tengo de dar limpio y descmbarazado el cementerio de la dicha iglesia cuando se acabe la dicha obra.

La cual me obligo de hacer a toda costa poniendo los materiales oficiales peones y demás adyacentes que sean necesarios sin que el dicho convento haya de dar ni poner cosa alguna más de tan solamente los oficiales y madera necesaria para apuntalar las madres. $Y$ por la dicha obra $y$ costa de ella se me ha de dar y pagar por el dicho convento diez mil pesos de a ocho reales pagados los dos mil y quinientos pesos de ellos habiendo acabado la cuarta parte de la dicha obra y otros dos mil y quinientos estando acabada la mitad de la dicha obra y otros dos mil y quinientos estando acabadas las tres cuartas partes y los dos mil y quinientos pesos restantes cumplimiento a toda la dicha cantidad estando acabada de todo punto la dicha obra la cual me obligo de dar perfectamente acabada conforme a la dicha traza y en la manera que dicho es dentro de cuatro meses que han de empezar a correr y contarse desde primero día del mes de febrero que vendrá rle este presente año en que estamos de la fecha de esta escritura y empezúndola desde el dicho día sin alzar mano de ella hasta la dejar acabada y a ello quiero ser compelido y apremiado por todo rigor de derecho $y$ prisión. $Y$ sin perjuicio de ello doy comisión al dicho Padre Maestro... (aiguen cláusulas notariales de obligación)... que es fecha la carta estando en el dicho convento a veinte y dos días del mes de enero año de mil y seiscientos y treinta y dos y los dichos otorgantes que yo el presente escribano doy fe conozco lo firmaron siendo testigos Antonio de Mendoza y Gregorio de Espinosa y Antonio de Medina presentes.

Fray Gabriel de Zárate

Prior Provincial
Antonio Mayordomo

\author{
anto mi \\ Juan de Valenzuela \\ escribano público
}




\section{I I}

\section{CONCIERTO: ANTONIO MAYORDOMO CON EL CONVENTO DE SANTO DOMINGO PARA ALARGAR EL CORO ALTO*}

Sepan cuantos esta carta vieren como yo Antonio Mayordomo maestro de albañilería residente en la ciudad de los Reyes del Perú de la una parte y de la otra el padre presentado Fray Alonso de Zárate Prior del convento de Nuestra Señora del Rosario y Orden de Predicadores fundado en la dicha ciudad y vicario provincial en nombre y por comisión que para ello tengo del muy reverendo padre presentado fray Miguel Correa, prior provincial de esta provincia otorgamos que somos convenidos y concertados en presencia del presente escribano y testigos de esta carta en tal manera que yo el dicho Antonio Mayordomo me obligo de alargar el coro alto del dicho convento hasta el pretil del cementerio conforme a la planta y montea que están hechas para este efecto y quedan en poder del padre fray Juan García maestro mayor del dicho convento y de la cual no exceder en manera alguna y quedan firmadas de mi mano y prior el dicho padre presentado fray Alonso de Zárate y del presente escribano público sacándola desde sus cimientos y hará en la dicha obra todo aquello que pídiere el dicho padre fray Juan García y toda la dicha obra ha de ser de cal ladrillo y piedra cal y arena y el material de dar y recibir y me obligo a la empezar desdo diez y seis días del mes de febrero que vendrá de este presente año de la fecha de esta escritura $y$ desde sus cimientos como dicho es y la daré acabada en lo que toca de albañilería a toda costa de materiales y peones y oficiales sin que el dicho convento me de cosa alguna porque es a mi cargo el hacerla como dicho es para en fin de marzo del año que viene de mil y seiscientos y treinta y cuatro. $Y$ se me ha de pagar por la dicha obra lo que se tasaro valer por idos terceros nombrados por cada parte el suyo sin que sea necesaria otra diligencia y la dicha paga se me ha de hacer en esta manera: estando hechas las bóvedas se me ha de dar y pagar tres mil pesos de a ocho reales y estando hechos los dos tercios de toda la dicha obra otros tres mil pesos y en estando acabada toda la dicha obra de todo punto el resto cumplimiento a toda la dicha cantidad que así se tasaro una paga en pos de otra llanamente y sin pleito alguno con las costas de la cobranza. Con lo cual me obligo a hacer la dicha obra en la forma dicha y de dar y recibir y en toda perfección y acabada para el plazo dicho sin alzar mano de ella y si así no lo hiciere y cumpliere consiento y tengo por bien que la parte del dicho convento del Señor Santo Domingo y su procurador en su nombre la pueda concertar

* AGN, escribano Juan de Valenzuela, 1633, protocolo 1964, folio 214 y sigtes. 
con otro oficial y por lo que más costare y lo que hubiere recibido consiento y tengo por bien ser ejecutado en mi persona y bienes y la dicha paga haré llanamente y sin pleito ... (siguen cláusulas notariales de obligación)... que es fecha la carta en los Reyes a catorce de febrero de mil y seiscientos y treinta $y$ tres años y los otorgantes que yo el presente escribano doy fe conozco, 10 firmaron testigos Juan de Aguilar y Melchor de Lerma Polanco y Manuel Carrasco presente.

Fray Alonso de Zárate

Antonio Mayordomo

Prior Vicario Prov.

\author{
anto $\mathrm{mi}$ \\ Juan de Valenzuela \\ escribano páblico
}

